\title{
32 Security for the Tokyo Olympics
}

Sebastian Polak-Rottmann

\section{Security and the Olympic Games}

Mega-events are often associated with potential threats of terrorism and other forms of unpredictable violence. In the case of the Olympic Games, security has a somewhat ambivalent relationship with the core values of the event. As social scientist Don Handelman puts it, surveillance and increasing "militarization and securitization of anything and everything relating to the Games" are a contradiction to the notion of peace championed during the event. ${ }^{1}$ In many cases the police work together with military forces and private security companies to cope with the increasingly complex structure of the Games. Some of the Games, however, could not succeed in meeting the high requirements of security: In the case of London, private security companies failed to employ the necessary amount of personnel - something that the Japanese Olympic Committee initially feared as well.

But security entails more than just security guards. It is rather something that "encompasses all kinds of domains of social activity." 2 Thus, security does not stop by just filling security gaps for the event but is rather actively involved in designing the event. Security is also crucial during construction: discussions in the Tokyo government frequently centered around the high amounts spent for the protection of the construction sites.

Of course, a high level of security is nothing exceptional during megaevents. However, how much security is "sufficient?" Security is not something tangible, nor visible, and it is easy to claim that security was insufficient in case something were to happen. In the eyes of the government or the organizers, major incidents during previous events have made surveillance a necessity for future Games. The attack on the Israeli Olympic team during the Munich Olympic Games in 1972 thus effectively shaped the understanding of security as an integral part of the Olympic Games and further catalyzed the enactment of security measures during 
the Games. ${ }^{3}$ At the 1964 Tokyo Games, local administration did not consider security a big issue, but rather wanted to show a positive image of a recovered and orderly Japanese nation. ${ }^{4}$ The Winter Olympics in Sapporo in 1972, however, proved to be different regarding security measures. As they took place during the "golden age of social movements" in Japan, attacks from protesters of different political camps inside Japan were feared by the organizers. The Sapporo Games thus helped to legitimize tighter security - mostly to deal with the "enemy within."

To what degree organizers or nations ultimately decide to enact security policies highly depends on potential threats or on past events which showed flaws in their security strategies. Considering the long history of the Games makes it understandable why the security apparatus has become bigger over time. In times of frequently occurring attacks on events and growing concerns about cyber security in the age of digital connectivity exemplified by the Internet of Things (IoT), who is able to provide this huge security apparatus during the 2020 Games?

\section{Securing 2020: cooperation and the pursuit of absolute security}

Since 2016, every year at the end of December, the Tokyo Organising Committee of the Olympic and Paralympic Games (TOCOG) presents the budget for the 2020 Games. Security expenses are scheduled to make up around $\$ 900$ million, $75 \%$ of which is covered by the Tokyo Metropolitan Government. Critical responses about too much security are hard to find.

Having the security during the Games in mind, the cabinet of Prime Minister Abe Shinzo announced the "Strategy for Japan as the safest country of the world" in December 2015, aiming to support the belief of the Japanese people in a "strong Japan" during the Games in 2020. In this report, the government lists "new threats" emerging from inside and outside Japan: cybercrime, cyberattacks, international terrorism, and organized crime. This emphasis on different forms of (mostly) organized crimes inside and outside cyberspace led to the establishment of an organization similar to the US NCFTA (National Cyber-Forensics and Training Alliance) and to the strengthening of existing systems. Since January 2015, located in the cabinet secretariat, the National Center of Incident Readiness and Strategy for Cybersecurity (NISC) is responsible for national cyber security. Preparing for the Tokyo Olympics, the NISC has gathered information on the cyber security environment of the previous three Games in London, Rio, and Pyeongchang. The organization refers to attacks by Anonymous in Rio, where both the websites of the government and the organizers had become targets, as well as the attacks on the networking 
systems at Pyeongchang. The NISC fears that this time around, as the Internet of Things (IoT) is spreading at a fast pace, potential attackers might target these devices in a concerted attack. The NISC thus has prepared numerous scenarios of possible risks and how they might wreak havoc onto the Games. The organization's homepage covers around 70 different case scenarios, including DDoS (distributed denial of service) attacks that may disrupt the internet service of the IOC or related organizations. While the NISC is part of the cabinet secretariat, the Olympic Committee has its own computer security incident response team that mainly engages in risk prevention strategies similar to its national counterpart. Chief Security Officer of the Olympic Committee, Yonemura Toshiro, former chief inspector of the Tokyo Police and advisor to the Abe Cabinet, summarizes the main activities of the planning as "imagination and preparation" (sōzo to junbi). He points to the importance of considering all possible risks in order to avoid the unexpected.

In March 2017, the previously established Security Directorial board announced the Main Strategy for Security during the Olympic and Paralympic Games in Tokyo 2020. This strategy introduces measures against threats during the event in more detail. One of the core elements is the establishment of security centers that will operate 24 hours-a-day at the Cabinet Secretariat to ensure a dense informational network during the Games, and to aid the police department in evaluating potential risks. In addition, this strategy emphasizes the close cooperation with private and public actors - something that is mentioned continuously within Japanese security discourse. This is especially interesting when considering the strict regulations for private security companies (PSC) in Japan. As private actors, these companies usually provide services only for the clients of their contract. However, especially during mega-events or natural disasters, the police department frequently asks for cooperation and relies on PSC staff and expertise. In joint statements, officials usually highlight the "important place within Japanese society" or the "responsibility and expectation for their engagement in security" of the private security industry. Even though employees of PSCs are not allowed to carry weapons and do not have any special rights concerning security in Japan, they have become an integral part of Japanese everyday life over the past decades.

During the Games, most of the security tasks on site will be fulfilled by a collaboration between police $(21,000)$ and PSC $(14,000)$, with SelfDefense Forces supporting the personnel. To ensure that there will be sufficient security guards available during the event, Japanese PSC created a joint venture. In addition, Japan's two largest security companies SECOM and ALSOK, who are official JOC partners, as well as several other 
companies agreed to collaborate. This strategy enables the different companies to effectively spread their staff flexibly to the various Games sites. This avoids small companies having to make their own contracts that would assign them to specific tasks, which would make it harder to react spontaneously to immediate requests. Compared to the previous Games in Tokyo in 1964, this time the venues are located in different areas of the city, which all require high levels of security. A flexible team of security guards is believed to be able to address this challenge smoothly. SECOM and ALSOK are confident that their approach will become a legacy of the 2020 Tokyo Olympic Games. They also hope that the event will further improve the level of the private security industry in Japan, which until now has been struggling with a bad reputation due to poor working conditions and low salaries.

While this joint venture is new for the Olympics, private security companies have been active during many large-scale events internationally for decades. However, these companies have a short history in Japan. In the 1960s, the first Japanese PSC - the predecessor of today's SECOM - was founded and received positive feedback during the 1964 Olympics. At first, Japanese citizens were reluctant to acknowledge their role in society as crime rates were low and they believed security to be something taken for granted. When crime rates started to rise in the 1980s, a feeling of insecurity grew within Japanese society, and even after they began declining since 2004, feelings of insecurity remain. Media reporting as well as official crime statistics matter to the sense of security in Japanese society. Official police statistics change over time, also depending on which crimes are included or excluded from the statistics. Sensationalized media reporting on crime statistics often do not take these changes into account. PSCs obviously profit from high feelings of insecurity, as it is their job to provide security. The numbers support this assumption: Over the past 45 years the number of private security personnel increased from 41,146 in 1972 to 552,405 in $2017,{ }^{6}$ by far outnumbering the police at 296,702 in 2018.

During the Games, these security guards will mainly be responsible for onsite security. They will check the incoming visitors at the gates, install moving security centers, and aid in traffic control. Especially the last service is very common in Japan. In case of repair work on the streets or construction sites, PSC staff are a regular sight for controlling traffic and pedestrian flows. During the Olympics, Japanese PSCs emphasize that they will try their best to ensure that security checks will be conducted swiftly in order to prevent congestion at the gates. Facial recognition, about 2.5 times faster than barcode scanning, will be used to speed up the check-in time. 


\section{Surveillance as a legacy of Tokyo 2020?}

How does Tokyo 2020 affect the city and what happens after the event? Even though security measures are generally accepted by the public to a certain degree, until recently there has been some resistance against the installment of security cameras in trains. Especially in its large urban centers, millions of Japanese commute daily by train, and many of the passengers take naps or surf the internet on their phones during their commutes. It was widely appreciated that - apart from a few trains - no cameras were in operation. However, crimes occurring on trains that received broad media coverage (such as a random knife attack on a Shinkansen bullet train in 2018) and the upcoming mega-event ultimately were used as sources of legitimation for tighter security measures. Once in operation, security cameras in trains or public spaces are not likely to be removed after the event. A large-scale advertising campaign by Tokyo Metro in 2019 tries to put a positive spin on camera surveillance in its stations and trains (see Figure 32.1). The tight cooperation between the police and the PSCs, once proven to be an effective method of crime prevention, will continue to be intensified. Just as during the Games in 1964, PSCs may once again receive positive feedback and will be assigned more tasks of social responsibility. 1964 was the opportunity to show that Japan is a country with advanced technology and back then, PSCs were still small in Japan. 2020, however, is the opportunity to present Japan as one of the world's safest countries. Although - or rather regardless of - a decreasing crime rate and increasing security awareness within Japanese society,

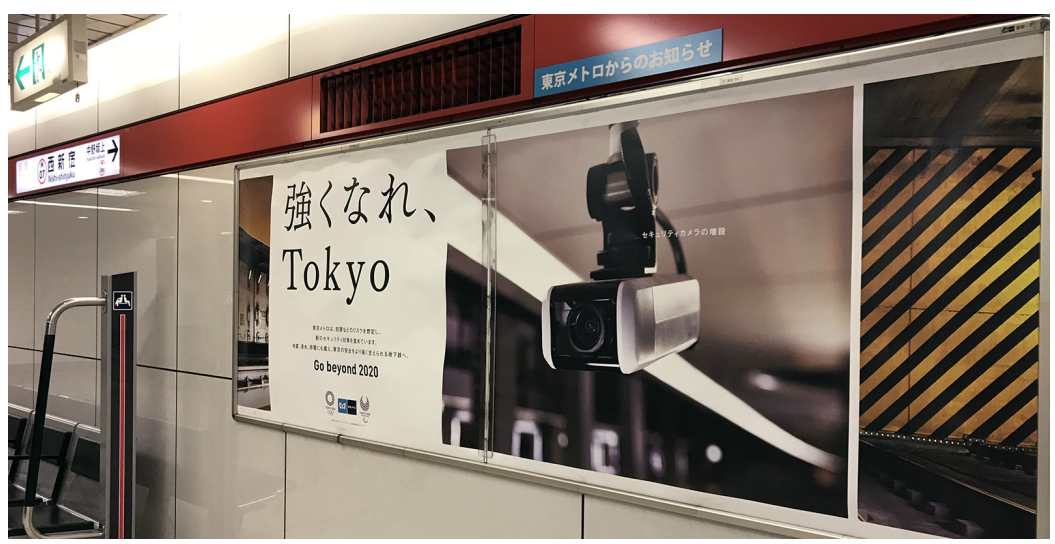

Figure 32.1 "Get strong, Tokyo", advertisement by Tokyo Metro.

Source: (c) Barbara Holthus. 
security measures for the Olympic Games will not only provide security, but also permanently change the role and meaning of security in Japanese society.

\section{Notes}

1 Handelman, Don. 2016. "Prologue: Olympic surveillance as a prelude to securitization." In Bajc, Vida (ed.). Surveilling and securing the Olympics. London: Palgrave Macmillan: 5.

2 Bajc, Vida. 2016. "The Olympic Games as a complex planned event: Between uncertainty and order through security meta-ritual.” In Bajc, Vida (ed.): Surveilling and securing the Olympics. London: Palgrave Macmillan: 24.

3 Ibid., 49.

4 Tagsold, Christian. 2016. "Modernity and the carnivalesque (Tokyo 1964)." In Bajc, Vida (ed.). Surveilling and securing the Olympics. London: Palgrave Macmillan: 107.

5 Abe, Kiyoshi. 2016. "Fear of the radical movements and policing the enemy within (Sapporo 1972)." In Bajc, Vida (ed.). Surveilling and securing the Olympics. London: Palgrave Macmillan: 141.

6 For 2017 data on PSCs in Japan, see www.npa.go.jp/safetylife/seianki/ statistics/29keibi.pdf. 